\title{
FRAKSINASI DAN IDENTIFIKASI SENYAWA ANTIKANKER EKSTRAK KULIT BATANG Rhizopora mucronata SERTA UJI TOKSISITASNYA TERHADAP LARVA UDANG
} (Artemia salina Leach)

\author{
Hartiwi Diastuti, Suwandri \\ Program Studi Kimia, Jurusan MIPA \\ Fakultas Sains dan Teknik, Universitas Jenderal Soedirman, Purwokerto
}

\begin{abstract}
Investigation the anticancer potency of $R$. mucronata has not been carried yet. This research were aimed to extract the bioactive compound of $R$. mucronata with various organic solvents, examine their toxicity againts A. salina Leach larv. and identify the toxic compounds from $R$. mucronata steam bark.

The extraction of $R$. mucronata steam bark were peformed by maseration with $\mathrm{n}$ hexane, chloroform, ethylacetate and methanol, repectively. The extracts were examined their toxicity againsts A. salina Leach larv. The highest activity extracts was fractionated performed by coloumn chromatography. The fractions respectively was examined their toxicity againts A. salina Leach larv. Identification of toxic compound was carry out using gas chromatography-mass spectrometry (GC-MS).

The chloroform extracts of $R$. mucronata had toxic character. Toxicity test to $A$. salina Leach larv. The Result showed that the chloroform fraction 1 (C1) of $R$. mucronata steam bark had $\mathrm{LC}_{50}$ equal to $301.50 \mathrm{ppm}$. Phytochemical study showed that the active fractions contained terpenoid. Bioactive compound from $R$. mucronata steam bark were dioctyl phthalate and cyclopropyle azulene decahydro-1,1,7-trimethyl-4-methylene.
\end{abstract}

Keywords : R. mucronata steam bark, anticancer, Artemia salina Leach.

\section{PENDAHULUAN}

Tumbuhan mangrove yang menempati kurang lebih 4 juta hektar wilayah Indonesia, merupakan sumber bahan obat tradisional yang dapat digunakan sebagai sumber senyawa bioaktif diantaranya golongan tanin, saponin, terpenoid, alkaloid dan steroid dengan aktivitas sebagai anti mikroba, antifungi, antivirus, antitumor, insektisida dan antileukemia (Soetarno, 2000 dan Ranutriwijaya, 1994). Pemanfaatan tanaman mangrove sebagai bahan obat tradisional telah lama digunakan oleh masyarakat dalam terapi penyakit gastroenteritis dan anti kanker. Bagian tumbuhan yang dapat digunakan sebagai anti kanker adalah kulit batang, akar, daun, bunga dan buah (Saputra,2000).
Tumbuhan mangrove juga menempati sekitar 15.000 hektar wilayah pantai Cilacap yang sebagian besar belum dikaji potensinya secara ilmiah. Salah satu famili tanaman mangrove yang tumbuh di pantai Cilacap yang diketahui berpotensi sebagai tananam obat adalah famili Rhizophoraceae. Warsinah, et al, (2005) melaporkan hasil penelitiannya tentang ekstrak etanol kulit batang $B$. gymnorhiza yang mampu menghambat pertumbuhan sel kanker Hela dengan nilai $\mathrm{LC}_{50}$ sebesar $301,78 \mu \mathrm{g} / \mathrm{ml}$ dan sel Myeloma dengan $\mathrm{LC}_{50}$ sebesar $582 \mu \mathrm{g} / \mathrm{ml}$ secara invitro. Ningsih, et al, (2006) dalam penelitiannya melaporkan adanya aktivitas antimikroba pada tanaman Rhizopora mucronata. Beberapa hasil penelitian menunjukkan bahwa tanaman 
yang diketahui memiliki aktivitas antimikroba, berpotensi pula sebagai antikanker, karena diduga toksisitas yang dimilikinya dapat pula bekerja pada fase tertentu dari siklus sel kanker (Lisdawati, 2002).

Ghosh et. al (1985) melaporkan adanya senyawa steroid, triterpenoid, alkaloid, flavonoid, tanin, katekat, kuinon dan antosianidin pada tanaman $R$. mucronata. Uji toksisitas ekstrak kulit batang $R$. Mucronata terhadap larva instar V H. Armigera yang dilaporkan oleh Nursal dan Pasaribu (2003) diketahui bahwa ekstrak etanol kulit batang $R$. Mucronata memiliki $\mathrm{LC}_{50}$ $3,22 \%$ pada suhu $30^{\circ} \mathrm{C}$ dan $\mathrm{LC}_{50} 2,10 \%$ pada suhu $24^{\circ} \mathrm{C}$. Uji toksisitas tersebut menunjukkan bahwa kulit batang $R$. Mucronata dapat digunakan sebagai insektisida.

Kanker merupakan salah satu ancaman utama di bidang kesehatan. Usaha penyembuhan kanker dengan obat (farmakoterapi) atau dengan senyawa kimia (khemoterapi) pada umumnya belum mampu memberikan hasil yang memuaskan, sehingga diupayakan caracara pengobatan alternatif antara lain dengan obat tradisional (Ma'at, 2004). Cara pengobatan dengan menggunakan tanaman obat tradisional tersebut umumnya belum mempunyai dasar rasional baik secara laboratoris maupun klinis.

Penelitian terhadap tumbuhan mangrove famili Rhizophoraceae, di antaranya pada spesies $R$. mucronata belum banyak dilaporkan, terutama kajian senyawa kimianya yang berpotensi sebagai antikanker. Penelitian ini dimaksudkan untuk melakukan uji pendahuluan terhadap ekstrak kulit batang $R$. mucronata tentang potensinya sebagai antikanker dengan metode uji kematian larva udang (Brine Shrime Lethality Test (BSLT)). Penelitian dilakukan dengan cara mengekstraksi kulit batang $R$. Rhizophora dengan metanol kemudian difraksinasi dengan beberapa pelarut yang berbeda kepolarannya (n-heksana, kloroform, dan etil asetat) serta menguji toksisitas setiap fraksi ekstrak sampel secara in vitro terhadap larva udang (Artemia salina Leach).

Manfaat penelitian ini adalah memberikan landasan ilmiah mengenai potensi anti kanker ekstrak kulit batang $R$. mucronata. Penemuan obat antikanker dengan agen fitoterapi menjadi penting artinya, karena dapat memberikan alternatif terapi dengan biaya yang jauh lebih murah dan seringkali memiliki efek samping yang lebih kecil.

\section{METODE PENELITIAN \\ Bahan dan Alat}

Bahan-bahan yang digunakan dalam penelitian ini adalah kulit batang $R$. mucronata dari pantai Tritih Cilacap Jawa Tengah, larva udang A. salina Leach, DMSO (dimetil sulfoksida), metanol, etanol, etil asetat, kloroform, dan n-heksana, silika gel untuk kolom kromatografi, pelat KLT serta kulit udang putih, $\mathrm{HCl}, \mathrm{NaOH}, \mathrm{NaOCl}$, kultur murni bakteri S. aureus ATCC 25293, nutrisi cair (NB), nutrisi padat (NA), akuades dan akuabides.

Peralatan yang digunakan dalam penelitian ini adalah : Alat-alat gelas yang biasa digunakan di laboratorium, kolom kromatografi, rotary evaporator, wadah biakan larva A. salina, lampu, kain hitam, kawat kassa dan GC-MS.

\section{Prosedur Penelitian \\ Ekstraksi dan Fraksinasi Serbuk Kulit Batang R. mucronata}

Kulit batang segar yang telah dibersihkan dari kotoran yang menempel, dikeringkan di tempat terbuka kemudian digiling halus. Serbuk kering yang diperoleh $(500 \mathrm{~g})$ dimaserasi dengan $n$ heksana selama 48 jam pada suhu kamar. Ekstrak disaring, kemudian pelarutnya diuapkan dengan rotary evaporator. 
Residu dikeringkan, selanjutnya diekstraksi kembali berturut-turut dengan pelarut kloroform, etil asetat dan metanol. Ekstraksi dengan pelarut bertingkat dimaksudkan untuk mendapatkan atau memisahkan ekstrak tumbuhan berdasarkan polaritas senyawanya.

Masing-masing ekstrak yang terlarut dalam n-heksana, kloroform, etil asetat dan metanol diuapkan pelarutnya. Ekstrak yang telah kering selanjutnya diuji toksisitasnya terhadap larva udang. Ekstrak dari pelarut tertentu yang memiliki toksisitas tertinggi digunakan untuk tahap isolasi dan identifikasi senyawa kimianya.

Ekstrak dari pelarut yang memiliki toksisitas terbesar selanjutnya di kromatografi kolom menggunakan silika gel $60 \mathrm{GF}_{254}$ sebagai penyangga fasa diam. Elusi dilakukan melalui elusi sistem gradien kepolaran dengan eluen yang sesuai. Fraksi hasil kromatografi kolom diuji KLT untuk mengidentifikasi komponen kimia dari setiap fraksi. Setiap fraksi yang sama digabung menjadi satu. Setiap fraksi gabungan diuji toksisitasnya terhadap larva udang A. salina Leach. Fraksi dengan aktivitas tertinggi diidentifikasi kandungan senyawa kimianya dengan pereaksi warna dan GCMS.

\section{Uji Toksisitas dengan Metode Uji Kematian Larva Udang (Dwiatmaka, 2000)}

Telur A. salina direndam ke dalam aquades selama 1 jam, telur yang tenggelam diambil untuk ditetaskan dalam air laut. Penetasan telur udang dilakukan dalam aquarium yang diberi aerasi selama 48 jam. Aquarium dibagi dua bagian dengan sekat kawat kassa. Satu bagian diberi telur udang dan ditutup dengan kertas karbon sedang bagian yang lain diberi penerangan dengan lampu. Larva akan bergerak dari tempat gelap ke tempat terang. Tabung berisi $10 \mathrm{~mL}$ air laut dan ekstrak disiapkan untuk memindahkan larva sebanyak 10 ekor, kemudian diamati jumlah larva udang yang mati kemudian dilanjutkan dengan penghitungan nilai LC $_{50}$. Ekstrak uji dibuat dengan konsentrasi 1000, 500, 250, 125 dan 62,5 $\mu \mathrm{g} / \mathrm{mL}$. Beberapa tetes DMSO dapat ditambahkan untuk membantu kelarutan ekstrak yang nonpolar.

\section{Uji Golongan Senyawa Kimia Fraksi Aktif (Harborne, 1987) \\ Uji flavonoid}

Larutan sampel ditambah dengan serbuk magnesium (pereaksi Shinoda) kemudian diberi beberapa tetes $\mathrm{HCl}$ pekat. Adanya senyawa flavonoid ditunjukkan dengan timbulnya warna oranye, merah muda dan ungu.

\section{Uji terpenoid}

Larutan sampel diteteskan ke dalam larutan Lieberman Buchard. Adanya senyawa terpenoid ditunjukkan dengan timbulnya warna biru, hijau, merah atau oranye.

\section{Uji alkaloid}

Larutan sampel ditambah dengan pereaksi Mayer selanjutnya ditambah beberapa tetes asam. Adanya alkaloid ditunjukkan dengan timbulnya endapan putih sampai kekuningan.

\section{HASIL DAN PEMBAHASAN Ekstraksi dan Uji Toksisitas Ekstrak Kulit Batang R. mucronata}

Ekstraksi serbuk kulit batang $R$. mucronata $(500 \mathrm{~g})$ dilakukan dengan cara sokletasi berturut-turut menggunakan pelarut n- heksana, kloroform, etil asetat dan metanol. Setiap ekstrak yang diperoleh selanjutnya dikeringkan dengan evaporator. Jumlah ekstrak kering dari kulit batang $R$. mucronata untuk masingmasing pelarut disajikan pada Tabel 1 . 
Tabel 1. Hasil ekstraksi kulit batang $R$. mucronata

\begin{tabular}{|l|c|c|}
\hline Ekstrak & $\begin{array}{c}\text { Jumlah } \\
\text { ekstrak }(\mathrm{g})\end{array}$ & $\begin{array}{c}\text { Rendemen } \\
(\%)\end{array}$ \\
\hline n-Heksana & 2,31 & 0,46 \\
\hline Kloroform & 3,00 & 0,60 \\
\hline Etil Asetat & 7,47 & 1,49 \\
\hline Metanol & 48,30 & 9,66 \\
\hline
\end{tabular}

Masing-masing ekstrak diuji toksisitasnya terhadap larva udang $A$. salina Leach untuk mengetahui nilai $\mathrm{LC}_{50}$ dari masing-masing ekstrak. Data hasil uji toksisitas selengkapnya disajikan pada Lampiran 1 dan nilai $\mathrm{LC}_{50}$ terhadap larva udang dapat dilihat pada Tabel 2 berikut.

Tabel 2. Nilai $\mathrm{LC}_{50}$ ekstrak kulit batang $R$. mucronata.

\begin{tabular}{|l|c|}
\hline Ekstrak & LC $_{50}(\mathrm{ppm})$ \\
\hline n-Heksana & 3014,98 \\
\hline Kloroform & 744,31 \\
\hline Etil Asetat & 1876,53 \\
\hline Metanol & 1063,41 \\
\hline
\end{tabular}

Hasil uji toksisitas ekstrak nheksana, kloroform, etil asetat dan metanol berdasarkan data pada Tabel 4.2 di atas menunjukkan bahwa ekstrak kloroform memiliki toksisitas tertinggi yaitu 744,31 ppm dan dinyatakan bersifat toksik serta berpotensi sebagai antikanker karena memiliki nilai $\mathrm{LC}_{50}$ kurang dari 1000 ppm. Sedangkan ekstrak n-heksana, etil asetat dan metanol bersifat tidak toksik karena memiliki nilai $\mathrm{LC}_{50}$ lebih besar dari 1000 ppm.

Ekstrak kloroform selanjutnya difraksinasi dengan kromatografi kolom menggunakan eluen n-heksan dan kloroform dengan perbandingan bervariasi berdasarkan urutan polaritas, dari polaritas terendah sampai dengan polaritas tertinggi. Hasil fraksinasi ekstrak kloroform menghasilkan 4 (empat) fraksi utama yaitu fraksi I, II, III dan IV, selanjutnya ke empat fraksi diidentifikasi dengan KLT menggunakan eluen kloroform : metanol $=9: 1$. Noda yang tampak pada KLT dihitung nilai Rf nya, kemudian diidentifikasi dengan lampu UV. Hasil KLT dapat dilihat pada Tabel 3.

Tabel 3. Hasil KLT fraksi ekstrak kloroform.

\begin{tabular}{|c|c|c|}
\hline Fraksi & Rf & $\begin{array}{c}\text { Warna noda } \\
\text { (lampu UV) }\end{array}$ \\
\hline I & 0,80 & Ungu \\
\hline II & 0,80 & Ungu \\
\hline III & 0,52 & Ungu \\
& 0,88 & Ungu \\
\hline IV & 0,52 & Ungu \\
& 0,88 & Ungu \\
\hline
\end{tabular}

Berdasarkan hasil KLT di atas, fraksi I dan II memiliki nilai Rf dan warna noda yang sama, sedangkan fraksi III memiliki profil yang sama dengan fraksi IV. Setiap fraksi dengan profil yang sama kemudian digabung sehingga diperoleh dua fraksi gabungan yaitu fraksi C1 dan fraksi C2.

Fraksi C1 dan fraksi C2 selanjutnya diuji toksisitasnya terhadap larva $A$. salina untuk mengetahui nilai $\mathrm{LC}_{50}$ dari masing-masing fraksi. Data hasil uji toksisitas terhadap larva $A$. salina dapat dilihat pada Lampiran 4 Berdasarkan data uji toksisitas diperoleh nilai $\mathrm{LC}_{50}$ untuk fraksi $\mathrm{C} 1$ yaitu sebesar 301,50 ppm sedangkan nilai $\mathrm{LC}_{50}$ untuk fraksi C2 sebesar 336,67 ppm. Fraksi dengan nilai $\mathrm{LC}_{50}$ terbesar yaitu fraksi $\mathrm{C} 1$ selanjutnya diidentifikasi senyawa kimianya dengan pereaksi warna untuk mengetahui golongan senyawanya dan dengan GCMS (Gas Chromatography 
Mass Spectrometer) untuk mengetahui tingkat pemisahan senyawa dan jenis senyawa kimianya.

\section{Identifikasi Senyawa Kimia Fraksi Aktif (C1)}

\section{Uji golongan senyawa}

Uji kualitatif golongan senyawa kimia dimaksudkan untuk mengetahui komponen kimia dari fraksi aktif yaitu fraksi C1 dari ekstrak metanol kloroform kulit batang $R$. mucronata yang bersifat toksik terhadap larva A. salina. Adapun hasil uji golongan senyawa kimia fraksi C1 kulit batang $R$. mucronata dapat dilihat pada Tabel 4 berikut:

Tabel 4. Hasil Uji kualitatif golongan senyawa ekstrak etanol $R$. Mucronata

\begin{tabular}{|l|c|c|c|}
\hline Sampel & Flavonoid & Terpenoid & Alkaloid \\
\hline Fraksi & -- & ++ & -- \\
C1 & (coklat) & (biru-ungu) & (coklat) \\
\hline
\end{tabular}

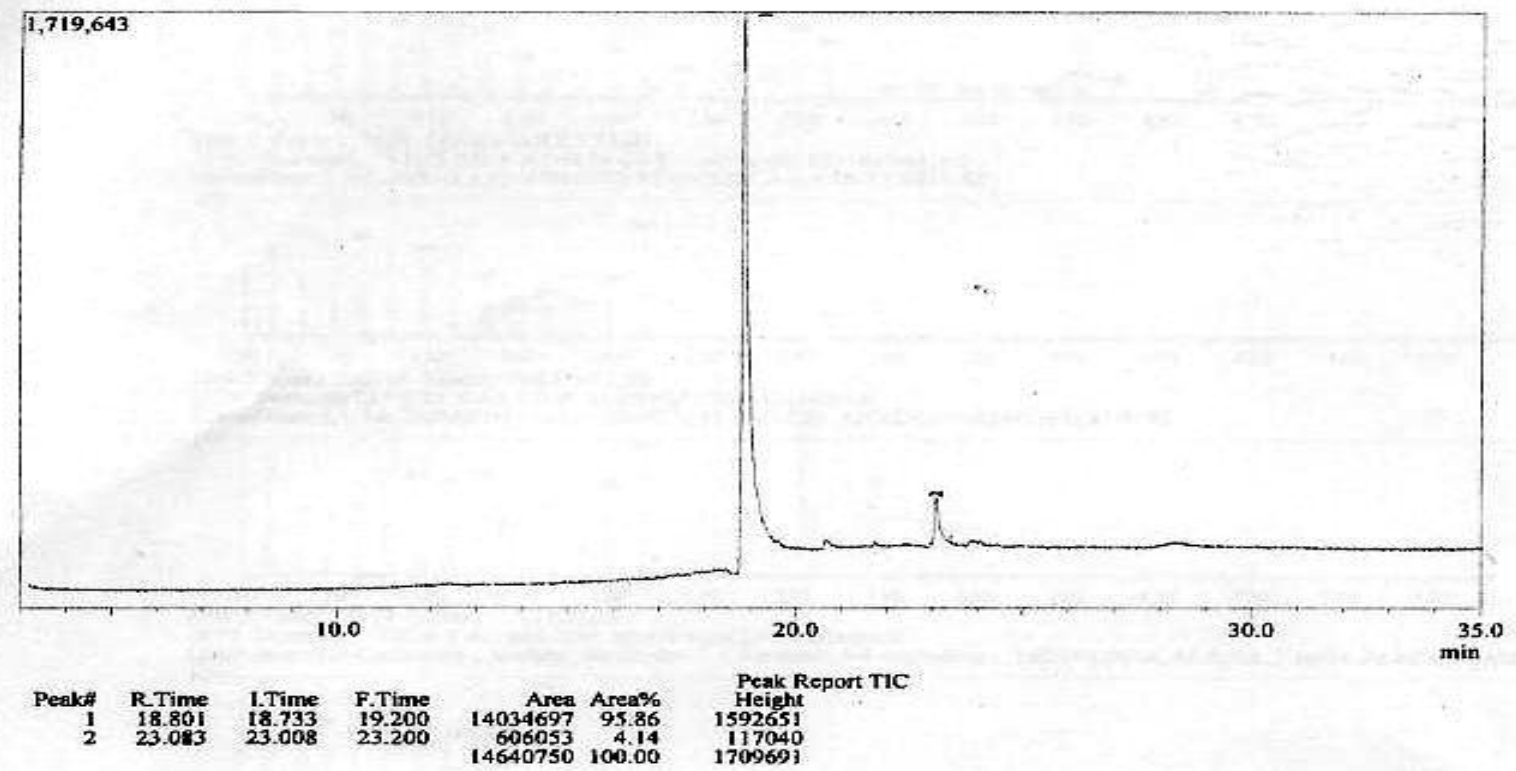

Gambar 1. Kromatogram fraksi C1

Hasil identifikasi senyawa berdasarkan spektrum massa menunjukkan bahwa kedua senyawa tersebut adalah senyawa dari golongan
Hasil uji dengan pereaksi warna menunjukkan bahwa fraksi kloroform ekstrak metanol kulit batang $R$. mucronata positif terhadap terpenoid sedangkan uji terhadap adanya senyawa flavonoid dan alkaloid diperoleh hasil negatif (tidak teridentifikasi).

\section{Analisis dengan GC-MS}

Hasil analisis fraksi $\mathrm{C} 1$ dengan GC-MS menunjukkan bahwa fraksi C1 minimum mengandung 2 senyawa yang ditunjukkan dengan adanya 2 puncak utama pada kromatogram yaitu pada waktu retensi 18,80 menit dan 23,08 menit. Kromatogram fraksi $\mathrm{C} 1$ dapat dilihat pada Gambar 1 di bawah ini. 
siklopropil azulena. Spektrum massa dilihat pada Gambar 2 dan 3.

dari kedua senyawa di atas dapat

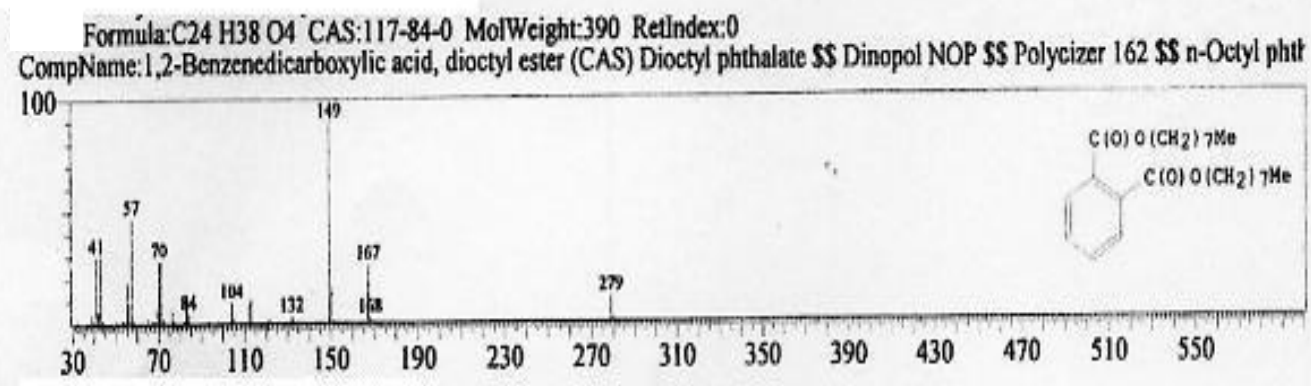

Gambar 2. Spektrum senyawa dioktilftalat

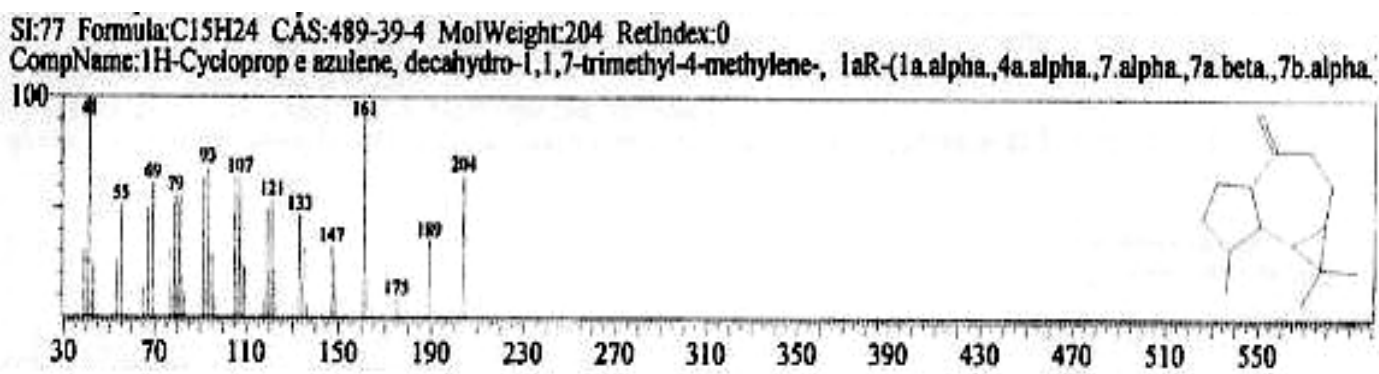

Gambar 3. Spektrum senyawa dekahidro-1,1,7-trimetil-4-metilena-siklopropil azulena

\section{KESIMPULAN}

Berdasarkan hasil penelitian diperoleh kesimpulan :

1. Hasil uji toksisitas terhadap larva udang A. salina menunjukkan bahwa ekstrak kloroform memiliki nilai $\mathrm{LC}_{50}$ tertinggi yaitu 744,31 ppm.

2. Hasil fraksinasi ekstrak kloroform diperoleh fraksi $\mathrm{C} 1$ dan fraksi $\mathrm{C} 2$ dengan nilai $\mathrm{LC}_{50}$ untuk fraksi $\mathrm{C} 1$ adalah sebesar $301,50 \quad$ ppm sedangkan nilai $\mathrm{LC}_{50}$ untuk fraksi $\mathrm{C} 2$ sebesar 336,67 ppm.

3. Hasil identifikasi senyawa dengan GC-MS menunjukkan bahwa fraksi C1 mengandung 2 senyawa dari golongan ester aromatik dikarboksilat yaitu dioktil ftalat dan senyawa dari golongan terpenoid azulena yaitu dekahidro-1,1,7- trimetil-4-metilena-siklopropil azulena.

\section{UCAPAN TERIMAKASIH}

Ucapan terimakasih kami sampaikan kepada Jurusan MIPA Unsoed yang telah memberi dana penelitian melalui dana DIPA MIPA Unsoed. 


\section{DAFTAR PUSTAKA}

Dwiatmaka, Y. 2000. Skrining Tanaman Berkhasiat Antikanker dengan Metode BST. Santa Darma. Yogyakarta.

Ghosh, A, S. Misra, AK. Duta, and A.Choudhury. 1985. Pentacyclic triterpenoids and Sterols from Seven Species of Mangrove. Phytochemistry. 24(8):1725-1727.

Harborne JB, 1987, Metode Fitokimia Penuntun Modern Menganalisis Tumbuhan, Edisi II, Penerbit ITB. Bandung.

Lisdawati, V. (2002). Buah Mahkota Dewa (Phaleria macrocarpa Boerl), Toksisitas, Efek Antioksidan dan Efek Antikanker berdasarkan Uji Penapisan Farmakologi.

http://ver.mahkotadewa.com/VFC /Vivi. htm. diakses tanggal 3 Juni 2007.

Ma'at, S. 2004. Obat Tradisional Untuk Pelayanan Kesehatan Formal. Prosiding Seminar Nasional. Tanggal 5 September 2004. Surabaya. P. 45-49.

Ningsih, D.R, Warsinah, dan Suwandri. 2006. Fraksinasi Ekstrak Metanol Kulit Batang Rhizophora mucronata dan Uji Daya Hambatnya Terhadap Bakteri
Escherechia coli. Molekul I(1) : 30-35.

Nursal dan N. Pasaribu.2003. Indeks Nutrisi Larva Instar V. Heliothis armigera Hubner pada Makanan yang Mengandung Ekstrak Kulit Batang Bakau (Rhizopora mucronata) dan Temperatur yang Berbeda.

http:/library.usu.ac.id/modules.ph p. Diakses 31 Mei 2007.

Ranutriwijaya, N. 1994. Telaah Fitokimia Daun Bakau (Rhizopora mucronata. Lamk). http//ftp.ui.edu/bebas/v12.artikel/t tg tanaman-obat/depkcs-2/buku 10.pdf. Diakses 31 Mei 2007.

Saputra, K., Ma'at, S., and Soedoko, R., 2000. Terapi Biologi Untuk Kanker. Airlangga University Press. Surabaya.

Soetarno, S.2000. Potensi dan Manfaat Tumbuhan Mangrove sebagai Sumber Bahan Bioaktif. Acta Pharmaceutica Indonesia. 12 (4) : 84-103.

Warsinah, P. Lestari, Trisnowati, 2005, Isolasi Senyawa Bioaktif pada Kulit Batang B. gymnorhiza Sebagai Bahan Antikanker. Laporan Penelitian Dasar. Program Sarjana MIPA UNSOED, tidak dipublikasikan 
Fraksinasi dan Identifikasi ...(Hartiwi Diastuti dan Suwandri)

\section{Lampiran 1.}

Data uji toksisitas ekstrak kulit batang $R$. mucronata terhadap A. salina Leach

\begin{tabular}{|c|c|c|c|c|c|}
\hline Ekstrak & $\begin{array}{c}\text { Konsentrasi } \\
(\mu \mathrm{g} / \mathrm{mL})\end{array}$ & $\begin{array}{l}\text { Rata-rata } \\
\text { hidup }\end{array}$ & $\%$ mati & log. kons & $\begin{array}{c}\mathbf{L C}_{50} \\
(\mu \mathrm{g} / \mathrm{mL})\end{array}$ \\
\hline \multirow[t]{4}{*}{ Heksana } & 500 & 8,00 & 20,00 & 2,70 & \multirow{4}{*}{3014,98} \\
\hline & 250 & 8,70 & 13,30 & 2,40 & \\
\hline & 125 & 8,70 & 13,30 & 2,10 & \\
\hline & 62,5 & 8,70 & 13,30 & 1,80 & \\
\hline \multirow[t]{4}{*}{ Kloroform } & 500 & 5,00 & 50,00 & 2,70 & \multirow{4}{*}{744,32} \\
\hline & 250 & 7,30 & 26,70 & 2,40 & \\
\hline & 125 & 7,70 & 23,70 & 2,10 & \\
\hline & 62,5 & 8,00 & 20,00 & 1,80 & \\
\hline \multirow[t]{4}{*}{ Etil asetat } & 500 & 6,00 & 40,00 & 2,70 & \multirow{4}{*}{1876,531} \\
\hline & 250 & 7,30 & 26,70 & 2,40 & \\
\hline & 125 & 5,70 & 43,30 & 2,10 & \\
\hline & 62,5 & 7,70 & 33,30 & 1,80 & \\
\hline \multirow[t]{4}{*}{ Metanol } & 500 & 4,00 & 60,00 & 2,70 & \multirow{4}{*}{1063,406} \\
\hline & 250 & 7,00 & 30,00 & 2,40 & \\
\hline & 125 & 8,30 & 16,70 & 2,10 & \\
\hline & 62,5 & 7,70 & 33,30 & 1,80 & \\
\hline
\end{tabular}

\section{Lampiran 2.}

Data uji toksisitas fraksi kloroform (C) kulit batang $R$. mucronata terhadap A. salina Leach

\begin{tabular}{|c|c|c|c|c|c|}
\hline Fraksi & $\begin{array}{c}\text { Konsentrasi } \\
(\mu \mathrm{g} / \mathrm{mL})\end{array}$ & $\begin{array}{c}\text { Rata-rata } \\
\text { hidup }\end{array}$ & $\%$ mati & $\log$. kons & $\begin{array}{c}\mathbf{L C}_{50} \\
(\mu \mathrm{g} / \mathbf{m L}) \\
\end{array}$ \\
\hline \multirow[t]{5}{*}{$\mathrm{C} 1$} & 1000 & 3,33 & 66,70 & 3,00 & \multirow{5}{*}{301,503} \\
\hline & 500 & 4,00 & 60,00 & 2,70 & \\
\hline & 250 & 7,67 & 23,33 & 2,40 & \\
\hline & 125 & 9,00 & 10,00 & 2,10 & \\
\hline & 62,5 & 9.00 & 10,00 & 1,80 & \\
\hline \multirow[t]{5}{*}{$\mathrm{C} 2$} & 1000 & 0,67 & 93,30 & 3,00 & \multirow{5}{*}{336,675} \\
\hline & 500 & 4,00 & 60,00 & 2,70 & \\
\hline & 250 & 7,00 & 30,00 & 2,40 & \\
\hline & 125 & 8,33 & 16,70 & 2,10 & \\
\hline & 62,5 & 8,67 & 13,30 & 1,80 & \\
\hline
\end{tabular}

